\title{
BMJ Open Coronary stenosis as a modifier of the effect of cold spells on the risk of sudden cardiac death: a case-crossover study in Finland
}

\author{
Niilo R I Ryti, ${ }^{1}$ M Juhani Junttila, ${ }^{2}$ Harri Antikainen, ${ }^{3}$ Marja-Leena Kortelainen, ${ }^{4}$ \\ Heikki V Huikuri, ${ }^{2}$ Jouni J K Jaakkola ${ }^{1}$
}

To cite: Ryti NRI, Junttila MJ, Antikainen $\mathrm{H}$, et al. Coronary stenosis as a modifier of the effect of cold spells on the risk of sudden cardiac death: a case-crossover study in Finland. BMJ Open 2018;8:e020865. doi:10.1136/ bmjopen-2017-020865

- Prepublication history for this paper is available online. To view these files, please visit the journal online (http://dx.doi org/10.1136/bmjopen-2017020865).

JJKJ and HVH have equal senior authorship.

Received 29 November 2017 Revised 18 April 2018 Accepted 18 June 2018

\section{Check for updates}

(C) Author(s) (or their employer(s)) 2018. Re-use permitted under CC BY-NC. No commercial re-use. See rights and permissions. Published by BMJ.

${ }^{1}$ Center for Environmental and Respiratory Health Research (CERH), University of Oulu, Oulu, Finland

${ }^{2}$ Research Unit of Internal Medicine, Medical Research Center Oulu, Oulu University Hospital, Oulu, Finland

${ }^{3}$ Geography Research Unit, University of Oulu, Oulu, Finland

${ }^{4}$ Department of Forensic Medicine, University of Oulu, Oulu, Finland

Correspondence to Professor Jouni J K Jaakkola; jouni.jaakkola@oulu.fi

\section{ABSTRACT}

Objective To test the a priori hypothesis that the association between cold spells and ischaemic sudden cardiac death (SCD) is modified by the severity of coronary stenosis.

Methods The home coordinates of 2572 autopsy-verified cases of ischaemic SCD aged $\geq 35$ in the Province of Oulu, Finland, were linked to 51 years of weather data. Cold spell was statistically defined for each home address as unusually cold weather pertinent to the location and time of year. We estimated the occurrence of cold spells during the hazard period (7 days preceding death) and reference periods (the same calendar days over 51 years) in a casecrossover setting applying conditional logistic regression, controlling for temporal trends and stratifying by severity of coronary stenosis.

Results The association between cold spells and ischaemic SCD was stronger among patients with 75\%95\% stenosis (OR 2.03; 95\% Cl 1.31 to 3.17 ), and weaker to non-existent among patients with $<75 \%$ stenosis (OR $0.97 ; 95 \% \mathrm{Cl} 0.37$ to 2.55 ) or coronary total occlusion (100\% stenosis) (OR 1.01; $95 \% \mathrm{Cl} 0.52$ to 1.96). Lack of calcium-channel blockers and statin therapy seemed to accentuate the role of stenosis during cold spells.

Conclusions We provide evidence that the association between cold spells and ischaemic SCD is modified by the severity of coronary stenosis. The findings suggest that disturbances in coronary circulation play part in the pathogenesis of SCD during cold weather.

\section{INTRODUCTION}

Sudden cardiac death (SCD) is a major global public health problem. ${ }^{1}$ Our recent case-crossover study provided evidence that the risk of ischaemic SCD is associated with cold spells. $^{2}$ The estimated association was stronger among patients whose diagnosis of ischaemic heart disease (IHD) was delayed until medicolegal autopsy and weaker among patients diagnosed during lifetime. Medications for IHD seemed to provide protection against SCD during cold spells. In particular, the risk of SCD during cold spells seemed greater among diagnosed cases without nitrate
Strengths and limitations of this study

- Cases from the world's largest autopsy-verified data set of sudden cardiac death were linked with 51 years of coordinate-specific weather data.

- Unusually cold weather was statistically defined for each home coordinate, resulting in location-specific and season-specific definition of cold spells.

- Methodological decisions were made to ensure that the results are directly comparable with previous findings, which the authors substantially elaborate.

- While these decisions enable formulation of a coherent synthesis with previous knowledge, statistical inference is limited by the lack of precision in the effect estimates.

therapy (OR 3.95; 95\% CI 1.52 to 10.25 ) than among cases who had been prescribed nitrates for their IHD (OR 0.52; 95\% CI 0.15 to 1.74). Similar effect modification was observed for aspirin (OR 1.90; 95\% CI 0.77 to 4.70 for non-users, and OR 1.02; $95 \%$ CI 0.34 to 3.08 for users) and $\beta$-blockers. ${ }^{2}$ These findings raise questions about the role of coronary circulation in cold-related pathogenesis of SCD. Here we hypothesised a priori that the association between cold spells and ischaemic SCD is modified by the severity of coronary stenosis.

\section{METHODS}

Our study population was 2572 consecutive cases of ischaemic SCD in the Province of Oulu, Northern Finland, 1998-2011, aged $\geq 35$ whose main cause of death was atherosclerotic heart disease (ICD-10 I25.1). This FinGesture database has been collected following a prospective study protocol. Case validation was conducted by a forensic specialist through medicolegal autopsy, histological analyses, toxicology, full medical 
history and police reports. The severity of coronary stenosis was assessed with the method of Champ and Coghill. ${ }^{3}$ We applied data, methods, criteria for SCD and study design identical with our two previous papers to allow direct comparability of the results and to improve external validity. ${ }^{24}$

We linked 51 years of coordinate-specific weather data in Geographical Information System (GIS) to the home coordinates of each case. We assigned each case a 7-day hazard period preceding the day of death and 50 reference periods comprising the same calendar days in 1961-2011. We formed a personal frequency distribution of daily temperatures during the hazard and reference periods for each case. Cold spell was defined as $\geq 3$ consecutive days with daily $\mathrm{T}_{\min }<5$ th percentile of the personal frequency distribution. We analysed whether potential differences in the occurrence of cold spells during the hazard and reference periods could be explained by random variation. We applied conditional logistic regression to estimate the ORs and $95 \%$ CIs for the association between cold spells and SCD, applying PROC PHREG in SAS V.9.4 with the discrete logistic model and forming a stratum for each ID. We formed an indicator variable consisting of 5-year intervals over the study period to control for long time trends. Season, month, day of the week and holidays were controlled by design.

We estimated the OR for the association between cold spells and SCD stratified by the severity of coronary stenosis using a priori cutpoints (moderate $<74 \%$; severe $75 \%-100 \%)$ and elaborated this by itemising coronary total occlusion (CTO).

\section{Patient and public involvement}

Patients and the public were not involved in the design or conduct of the study, formulation of research questions and outcome measures, or the recruitment process.

\section{RESULTS}

A total of 2817 cold spells were identified. The lowest temperature at the home coordinates during the evaluated periods was $-45.8^{\circ} \mathrm{C}$ and the highest was $+21.9^{\circ} \mathrm{C}$, with an overall temperature range of $67.7^{\circ} \mathrm{C}$. Of the 2572 cases with SCD, $80 \%$ were men and $20 \%$ women. Forty-four per cent were aged 35-64 years and 56\% were aged 65 years or more. Details of the study population, including their use of medications, diagnostic status and season of death, have been previously described. ${ }^{24}$

The association between cold spells and ischaemic SCD was stronger among patients with severe stenosis (OR 1.60; 95\% CI 1.11 to 2.30) compared with patients with moderate stenosis (OR $0.97 ; 95 \%$ CI 0.37 to 2.55 ) (table 1). Elaborated, the association between cold spells and SCD was strongest among patients with 75\%-95\% stenosis (OR 2.03; 95\% CI 1.31 to 3.17) and non-existent among patients with CTO (100\% stenosis) (OR 1.01; $95 \%$ CI 0.52 to 1.96 ). The latter might indicate collateral circulation and is consistent with our hypothesis. Lack of calcium-channel blockers (CCB) and statin therapy seemed to accentuate the role of stenosis during cold spells (table 1).

With the exception of 'No CCB therapy' and 'No statin therapy', the effect estimates in the column 'All cases' in table 1 have been previously published ${ }^{2}$ and are reproduced here for comparison (Creative Commons Attribution Non Commercial CC BY-NC 4.0 licence).

\section{DISCUSSION}

We provide empirical evidence that the association between cold spells and SCD is stronger among patients with severe coronary stenosis compared with those without, i.e. coronary stenosis serves as an effect modifier of the association. This is interesting, since the severity of coronary stenosis is not considered a reliable predictor of acute ischaemic event, and it does not necessarily correlate with ischaemia-related symptoms. ${ }^{5}$ We believe that, tangent to the current opinion, it is reasonable to suspect that cold weather creates special circumstances under which coronary stenosis can predispose patients to transient myocardial ischaemia, i.e. predict SCD during cold weather.

Table 1 Effect of cold spells on the risk of ischaemic SCD by severity of coronary stenosis

\begin{tabular}{llll}
\hline & Moderate stenosis & Severe stenosis & All cases \\
\hline All cases, $\mathrm{n}(\%)$ & $512(19.91)$ & $2060(80.09)$ & $2572(100.00)$ \\
\hline All cases, OR $(95 \% \mathrm{Cl})$ & $0.97(0.37$ to 2.55$)$ & $1.60(1.11$ to 2.30$)$ & $1.49(1.06$ to 2.09$)$ \\
\hline Diagnosis of IHD before death & & & $823(100.00)$ \\
\hline Yes, $\mathrm{n}(\%)$ & $101(12.27)$ & $722(87.73)$ & $1749(100.00)$ \\
\hline No, $\mathrm{n}(\%)$ & $411(23.50)$ & $1338(76.50)$ & $1.14(0.61$ to 2.10$)$ \\
\hline Yes, OR $(95 \% \mathrm{Cl})$ & - & $1.24(0.67$ to 2.31$)$ & $1.70(1.13$ to 2.56$)$ \\
\hline No, OR $(95 \% \mathrm{Cl})$ & $1.18(0.44$ to 3.17$)$ & $1.85(1.18$ to 2.91$)$ & $1.88(1.28$ to 2.75$)$ \\
\hline No CCB therapy & $1.17(0.44$ to 3.14$)$ & $2.07(1.36$ to 3.14$)$ & $1.46(0.97$ to 2.22$)$ \\
\hline No statin therapy & $0.72(0.21$ to 2.46$)$ & $1.66(1.06$ to 2.59$)$ & \\
\hline
\end{tabular}

CCB, calcium-channel blockers; IHD, ischaemic heart disease; SCD, sudden cardiac death. 
The following mechanisms might introduce synergistic effects between coronary stenosis and cold exposure in the risk of SCD: First, both coronary stenosis and cold exposure increase the risk of instabile plaque rupture, the latter via substantially and immediately increased blood pressure. ${ }^{6}$ In our studies lack of antihypertensive medications and lack of pleiotropic statins, which stabilise coronary plaques, ${ }^{7}$ increased the risk of SCD associated with cold spells. Second, both coronary stenosis and cold exposure increase the risk of thrombosis. ${ }^{58}$ In our studies aspirin reduced the risk of SCD associated with cold spells. Third, both coronary stenosis and cold exposure increase the risk of coronary spasm. ${ }^{10-12}$ Endothelial dysfunction related to coronary atherosclerosis is a promoter of coronary spasms, and the majority of spasms seem to occur at the sites of atherosclerotic lesions. ${ }^{10} \mathrm{CCBs}$ and nitrates are elemental in the prevention of coronary spasms, ${ }^{13} 14$ and there are promising results on statins also. ${ }^{15}$ In our studies lack of nitrates, CCBs and statins increased the risk of SCD associated with cold spells. Fourth, both coronary stenosis and cold exposure can precipitate a mismatch between myocardial oxygen supply and demand, ${ }^{16}$ creating transient ischaemic changes predisposing to electrical instability and ventricular fibrillation. ${ }^{17}$ In our studies lack of nitrates (influencing oxygen supply) and $\beta$-blockers (influencing oxygen demand) increased the risk of SCD associated with cold spells.

Although SCD pathogenesis is not commonly considered in the context of cold weather, the theory presented above is in perfect alignment with the current paradigm of $\mathrm{SCD},{ }^{17}$ in which transient ischaemic changes in the diseased heart can trigger life-threatening arrhythmias leading to SCD (substrate-trigger paradigm). The fact that fresh myocardial infarction scar was not common in our population is consistent with the paradigm, and further underlines the well-known differences between SCD and acute myocardial infarction. ${ }^{18}$

\section{Limitations}

It was not possible to confirm or assess the probabilities of the suggested pathological mechanisms in our study, and it was not possible to formally assess synergy between coronary stenosis and cold spells. Causal inference is limited by lack of precision in the effect estimates. This is a major limitation of the study. Inference is based on a hierarchical series of causal hypotheses and synthesis with prior evidence. ${ }^{24}$ While the array of point estimates, particularly when considered together with our previous findings, permits a coherent synthesis, this synthesis should be treated as qualitative in nature.

We did not have more detailed data on the status of the coronary arteries, so it was not possible to elaborate potential differences in effect modification between cases with single-vessel and multivessel disease. Coronary stenosis may be an indicator of susceptibility to the effects of cold weather, and it may be associated with other individual factors increasing susceptibility. It should be clarified that weather, however, is not influenced by individual characteristics, and therefore our analyses based on comparison of the occurrence of cold spells during the two period types in each home coordinate will not be confounded by such factors.

We did not have air pollution data in our study, and using it would have compromised our objective of producing effect estimates that are directly comparable with those from the two previous studies. Elaborating the meteorological components and characteristics of cold spells would be a meaningful future task, facilitating the development of meteorological alarm systems.

The study was conducted in subarctic climatic conditions and the findings may not be generalisable to other types of climates. However, our method of statistically defining relative cold spells is not climate-dependent. Our methods are also not population-dependent. We adopted an explicit and recognised definition of SCD, and all cases were validated by medicolegal autopsy. Applying these methods should produce directly comparable, but not necessarily identical, results in different climates and populations around the world. However, since our three studies on the associations between cold spells and SCD seem to remain the only ones on the topic, it is difficult to speculate on the strength of associations in other settings.

\section{CONCLUSIONS}

Our findings suggest that disturbances in coronary circulation may play part in the pathogenesis of SCD during cold spells. While much remains to be elaborated, the results stimulate interesting questions. Could it be one day possible to predict some SCDs by looking at the weather forecast? What kind of pre-emptive advice should we then give to patients at risk?

Contributors NRIR and JJKJ designed the case-crossover study with clinical input from MJJ and HVH. M-LK performed the medicolegal autopsies during 1998-2011. MJJ and HVH constructed the sudden cardiac death database. HA constructed the weather database and performed the GIS-modeling of daily temperatures at each location. NRIR performed the SAS-programming of weather indices, modeling of health effects, and statistical analyses, and drafted the manuscript with important intellectual content from all authors. All authors approved the version to be published and agreed to be accountable for all aspects of the work.

Funding This work was funded by the Research Council for Health, Academy of Finland (grant nos 266314 and 267435), University of Oulu Strategic Funding for CERH, Emil Aaltonen Foundation, Sigrid Juselius Foundation and Foundation for Cardiovascular Disease. The funders of the study had no role in study design, data collection, data analysis, data interpretation, writing of the report or the decision to submit the article for publication. The authors are independent from funders.

Competing interests None declared.

Patient consent Not required.

Ethics approval This study complies with the Declaration of Helsinki and has been approved by the Ethics Committee of the Oulu University Hospital (ID of the approval EETTMK:18/2014). The National Supervisory Authority for Welfare and Health (Valvira) has approved the review of postmortem data by the investigators.

Provenance and peer review Not commissioned; externally peer reviewed. Data sharing statement No additional data available.

Open access This is an open access article distributed in accordance with the Creative Commons Attribution Non Commercial (CC BY-NC 4.0) license, which permits others to distribute, remix, adapt, build upon this work non-commercially, and license their derivative works on different terms, provided the original work is 
properly cited, appropriate credit is given, any changes made indicated, and the use is non-commercial. See: http://creativecommons.org/licenses/by-nc/4.0/.

\section{REFERENCES}

1. Adabag AS, Luepker RV, Roger VL, et al. Sudden cardiac death: epidemiology and risk factors. Nat Rev Cardiol 2010;7:216-25.

2. Ryti NR, Mäkikyrö EM, Antikainen $\mathrm{H}$, et al. Cold spells and ischaemic sudden cardiac death: effect modification by prior diagnosis of ischaemic heart disease and cardioprotective medication. Sci Rep 2017;7:41060.

3. Champ CS, Coghill SB. Visual aid for quick assessment of coronary artery stenosis at necropsy. J Clin Pathol 1989;42:887-8.

4. Ryti NRI, Mäkikyrö EMS, Antikainen $\mathrm{H}$, et al. Risk of sudden cardiac death in relation to season-specific cold spells: a case-crossover study in Finland. BMJ Open 2017;7:e017398.

5. Virmani R, Burke AP, Farb A, et al. Pathology of the vulnerable plaque. J Am Coll Cardiol 2006;47(8 Suppl):C13-18.

6. Hintsala H, Kandelberg A, Herzig KH, et al. Central aortic blood pressure of hypertensive men during short-term cold exposure. Am J Hypertens 2014;27:656-64.

7. Ray KK, Cannon CP. The potential relevance of the multiple lipidindependent (pleiotropic) effects of statins in the management of acute coronary syndromes. J Am Coll Cardiol 2005;46:1425-33.

8. Sakariassen KS, Orning L, Turitto VT. The impact of blood shear rate on arterial thrombus formation. Future Sci OA 2015;1:FSO30.
9. Keatinge WR, Coleshaw SR, Cotter F, et al. Increases in platelet and red cell counts, blood viscosity, and arterial pressure during mild surface cooling: factors in mortality from coronary and cerebral thrombosis in winter. Br Med J 1984;289:1405-8.

10. Bertrand ME, LaBlanche JM, Tilmant PY, et al. Frequency of provoked coronary arterial spasm in 1089 consecutive patients undergoing coronary arteriography. Circulation 1982;65:1299-306.

11. Raizner AE, Chahine RA, Ishimori T, et al. Provocation of coronary artery spasm by the cold pressor test. Circulation 1980;62:925-32.

12. Ghaffari S, Pourafkari L. Coronary spasm provocation with cold pressor test. Intern Emerg Med 2010;5:559-60.

13. JCS Joint Working Group. Guidelines for diagnosis and treatment of patients with vasospastic angina (Coronary Spastic Angina) (JCS 2013). Circ J 2014;78:2779-801.

14. Slavich M, Patel RS. Coronary artery spasm: current knowledge and residual uncertainties. Int J Cardiol Heart Vasc 2016;10:47-53.

15. Yasue H, Mizuno Y, Harada E, et al. Effects of a 3-hydroxy-3methylglutaryl coenzyme A reductase inhibitor, fluvastatin, on coronary spasm after withdrawal of calcium-channel blockers. J Am Coll Cardiol 2008;51:1742-8.

16. Manou-Stathopoulou V, Goodwin CD, Patterson T, et al. The effects of cold and exercise on the cardiovascular system. Heart 2015;101:808-20.

17. Myerburg RJ, Junttila MJ. Sudden cardiac death caused by coronary heart disease. Circulation 2012;125:1043-52.

18. WHO Scientific Group on Sudden Cardiac Death. Sudden cardiac death. Geneva Switzerland: World Health Organization, 1985. 